\title{
Loneliness and Locus of Control among Adolescents Belonging To Nuclear and Joint Families
}

\author{
Nikhat Kaura $^{1 *}$, Dr Roopali Sharma ${ }^{2}$
}

\section{ABSTRACT}

Family plays a very prominent and important role in an adolescent's life. Adolescents may encounter rejections and subsequently develop the feeling of loneliness. The study aims to investigate loneliness and locus of control among adolescents belonging to joint and nuclear families. A total of 120 adolescents (males=60; females=60) in age range of 15-17 years residing in nuclear and joint families. Locus of Control Scale Indian Adaptation of Levensons Scale (Vohra, 1992) and Perceived Loneliness Scale (Jha, 1997) were administered to the participants. Analysis of variance revealed that the adolescents belonging to nuclear and joint families significantly differed on loneliness score. Results indicated that there was no difference between powerful others, chance control (external factors) and adolescents in nuclear and joint families, and individual control (internal factors) and adolescents in nuclear and joint families. Hence, it can be concluded that adolescents in nuclear families were lonelier as compared to adolescents in joint families. The study also shows that adolescents residing in joint families possessed higher internal locus of control whereas adolescents from nuclear families had higher external locus of control.

Keywords: Adolescents, Nuclear and Joint Family, Loneliness, Locus of Control

When a child is born, the first thing he encounters is his or her family. It holds utmost importance in an individual's life. A child learns the first few concepts from his family and environment around him. First relationship of an individual is with his family, and the quality of the relationship established with the family determines future life and behaviours. There are times when an individual feels lonely while he/she is around his/her family. This can emerge when children or adolescents feel that they do not have any meaningful social relationship, and also when the support system provided by family or social media is lacking.

Family structure is conceptualized as the configuration of role, power and status, and relationships in the family. There are two types of family structures: traditional and nuclear. Traditional family is the one living jointly and consists of members from different generations.

\footnotetext{
${ }^{1}$ Research Scholar, AIPS, Amity University, Noida

2 Associate Professor, AIPS, Amity University, Noida

*Corresponding Author

(C) 2015 I N Kaura, R Sharma; licensee IJIP. This is an Open Access Research distributed under the terms of the Creative Commons Attribution License (http://creativecommons.org/licenses/by/2.0), which permits unrestricted use, distribution, and reproduction in any Medium, provided the original work is properly cited.
} 


\section{Loneliness and Locus of Control among Adolescents Belonging To Nuclear and Joint Families}

Nuclear type of family is the one, in which the group consists of a male, his wife and their children.

A study done by Ditommaso et al. (2005), found out that there exists a meaningful relation between feeling of loneliness, and culture and family. The study shows that in a culture which lays emphasis on family, an individual feels less lonely than in a culture where a family is not given sufficient emphasis.

As adolescents start to move beyond the circle of family to groups and schools, they may encounter rejection by peers. Indeed, they are vulnerable to loneliness and it continues throughout life.

Loneliness is a universal phenomenon, and every individual experiences it at some point of time in their lives. Some people live it day after day for years on end. The feeling of loneliness can be emotionally depleting and psychologically regressing. It occurs when an individual comes across unpleasant experiences and his network of social relationships is significantly deficient, either qualitatively or quantitatively (Peplau \& Perlman, 1981). Such a feeling of loneliness results from a mismatch between an individual exists social relationships and what they view as ideal, which leads to a psychologically uncomfortable situation (Ponzetti, 1990). Arnett, (2007) stated that it is psychological mode caused by the weakness of personal communication and socialization skills.

Reasons for loneliness may include lack of friendship relations during childhood and adolescence, physical absence of meaningful people, developmental changes, separation from parents and struggle for significance (Brennan, 1982). Factors that influence loneliness can be broadly classified into individual factors which are embedded in one's personality, and situational factors such as peer experiences (Weiss, 1982).

Loneliness is a common problem among adolescents. This age group represents a complex transition from childhood to adulthood, which inevitably implies new challenges. These challenges include aspects related to mental well-being that not only stem from changes in relationships and demands related to the emergence into adulthood in a globalised world, but also from existential thoughts and developmental changes (Rutter and Smith 1995; Zubrick et al. 2000).

While adolescents undergo change in their emotions, their thoughts and behaviour differ from that of their parents and what different values they hold than to those of their family. Owing to such thoughts, adolescents are required to make a huge effort to accept who they are, find themselves, make new friends and reach their aims (Nelsen \& Lott, 2001). This period of struggle and indecisiveness changes their emotions and interests. Thus resulting tension makes adolescents depressed and lonely. During this period they feel suffocated and restless; and 
desperately need the security of a comforting environment (Kulaksizoğlu, 2001). The lack of such an environment may also instil a feeling of loneliness in adolescents. If such feelings in adolescents remain unresolved, it can lead to anxiety and social avoidance which then becomes an obstacle in the formation of normative social relationships (Lau \& Kong, 1999; Vernberg, Ewell, Beery, \& Abwender, 1994).

\section{LOCUS OF CONTROL}

Who the individual is largely defined by the experiences he has had and how he understands those experiences (McLean, 2007) and where it is influenced by his internal factors i.e. his personal attributes, or external factors, i.e., forces outside him. Locus of Control is a measure of how individuals believe they can control their life, how they can control the events affecting them and where that control comes from.

Locus of control is an individual's expectancies for internal (i.e., by oneself) versus external (i.e., by fate, chance, luck, or powerful others) control of reinforcement (Jolley \& Spielberger, 1973). Locus of control is defined as one's thoughts of his/her belief that his/her own power or forces out of his/her control are influential in any positive or negative situation occurring during his/her life (Sardogan, 2006).

When an individual thinks that he is not efficient and he is not able to explain his outcomes, the feeling may lead to low motivation. So, locus of control can be seen as bipolar construct, ranging from external causes to internal causes. (Bender, 1995, Basgall and Snyder, 1988, Marsh \& Richards, 1987)

Therefore locus of control can be divided into internal and external locus of control. Internal locus of control is the perception that events are contingent on one's own, while external locus of control is characterized by the feeling that outcomes are more a result of fate, luck, chance or control of powerful others, or are unpredictable due to the complexity of situations. People with internal locus of control believe they control their own destiny. They tend to be convinced that their own skill, ability and efforts determine the bulk of their life experiences. In contrast, people with external locus of control believe that their lives are determined mainly by sources outside themselves (Rotter, 1954; Adas, 1999).

Studying locus of control is an important aspect of adolescent and its personality. Locus of control is affected by a number of factors like age, socioeconomic status, family style, etc. Family style and cultural stability are associated with the development of locus of control. Research in this area shows that adolescents' whose family environment is characterized by warmth, protection, and nurturance are more likely to develop an internal locus of control while those with limited social power or material resources are more likely to develop external locus of control. It has also been seen that many internals have grown up with families that modeled 
typical internal beliefs. But some earlier studies suggest that locus of control and family are not related.

So it can be concluded that locus of control (internal and external) is an important factor of study with influence on family and adolescents that are belonging to it.

The purpose of the study is to examine how adolescents in joint and nuclear families differ on the locus of control factor and also how loneliness differs in adolescents from joint and nuclear families.

\section{REVIEW OF LITERATURE}

The relationship of locus of control with mental health and adjustment among adolescents (females) has been recently studied Jain and Singh (2015). The study suggests that adolescent females with internal locus of control adapt more easily to various situations across domains including social and emotional domains. It also suggests significant influence of locus of control on mental health and adjustment among adolescent females.

Rehman and Singh (2015) studied the family type and adjustment level of adolescents. The study found that adolescents from joint families adapt better compared to adolescents from nuclear families. Similarly, gender was found to have a significant relation with adjustment levels among adolescents; girls have higher adjustment levels than boys.

Shinde and Bhoi (2014) provide a comparative study of social adjustment of adolescents based on nuclear and joint family types, and conclude that there is a significant relationship between social adjustment and family type.

Javeed (2014) researched the effect of nuclear family and joint family upon emotional intelligence and loneliness of children. The study was undertaken using 100 nuclear family child and 100 joint family children of Aurangabad town. The result of the above research showed that Nuclear family children have significantly high loneliness than the Joint family children.

Pattankar (2014) states that there lies no significant difference between joint and nuclear families and powerful factor of locus of control among athletes.

Usoroh et al. (2014) did a comparative study of the effect of family types on social adjustment of adolescents among joint and nuclear families. The study reveals that family type has a significant relationship with adolescents' social adjustment levels.

Khazer and Almajali (2012) studyaimed to find out whether Jordanian middle school learners' locus of control is related to their parent's upbringing style. Results showed that there is a clear relationship between two factors. Gender did not reveal any significance on any of the two factors. 
Selvaraj and Gnanadevan (2012) studied the loneliness of higher secondary students. The higher secondary students belonging to nuclear family and joint family differ significantly in their level of loneliness, and the level of loneliness is high for the students belonging to nuclear family than the students belonging to joint family.

Similarly, study conducted by Attar-Schwartz et al. (2009) suggests that adolescents who spend time with their grandparents have better social and emotional adjustment levels, and have fewer behavioural problems.

Gürsoy and Bıçakçı (2006) studied to analyse whether the variables of gender, socioeconomic status, and family and friend relationships affect the loneliness levels of adolescents. The result showed that family and loneliness have significant difference among adolescents.

\section{METHODOLOGY}

AIM

To study how Loneliness and Locus of Control differs in Adolescents Belonging to both Nuclear and Joint families.

OBJECTIVES OF THE STUDY:

1. To measure the effect of family type on loneliness and locus of control among adolescents belonging to joint and nuclear families.

\section{HYPOTHESES:}

1. The level of loneliness among adolescents from nuclear and joint families will differ significantly.

2. There will be significant difference among adolescents belonging to nuclear and joint families on the powerful others factor of locus of control.

3. Adolescents belonging to nuclear and joint families will differ significantly on the chance control factor of locus of control.

\section{School Going Adolescent}

(15 -17 years)

4. Individual control factor of locus of control will differ significantly among adolescents from nuclear and joint families.

\section{SAMPLE}

In the present study total number of sample includes 120 school going adolescents (60 nuclear family and 60 joint family adolescents). The age of the teenagers ranges from 15 to 17 years. Sample collection was done from private schools in Delhi and NCR. 
Loneliness and Locus of Control among Adolescents Belonging To Nuclear and Joint Families

\begin{tabular}{|l|l|l|}
\hline Family type & Nuclear families & Joint families \\
\hline \multirow{2}{*}{ Total } & 60 & 60 \\
\cline { 2 - 3 } & 120 & \\
\hline
\end{tabular}

TOOLS USED:

1. Locus of Control Scale Indian Adaptation of Levensons Scale (Vohra, 1992) :

The locus of control scale contains 24 statements covering the areas like Powerful others (P), Individual control (I) and Chance control (C). The test retest reliability coefficient was found to be 0.76 . The present scale was validated against the Rotter's Locus of control scale i.e. the concurrent validity was established. Scores of both the scales were then correlated with each other and the correlation co-efficient was found to be 0.54 .

2. Perceived Loneliness Scale (jha, 1997):-

It consists of 36 items in the scale that are rated on a five point Likert type scale ranging from 1 (totally disagree) to 5 (totally agree). The obtained test-retest reliability coefficients 0.84 and validity of loneliness-scale was examined by three ways: Content, predictive and concurrent validity.

PROCEDURE: -

For the purpose of present research prior permission to conduct psychological test was taken from different schools principles. A rapport was established with the adolescent between age group of 15-17 years to create comforting environment thereby ensuring genuine responses. Before distributing the scales, they were properly oriented about the tests and proper instructions were given to all. Students were given the confidence that the test was conducted purely for research purposes and that the results will remain confidential. After the scale was filled they were collected by the researcher in person.

STATISTICAL ANALYSIS:-

After conducting the research, the data was put for statistical analysis. In the first step the raw data was put in to calculate the mean and standard deviation. Further analysis of variance was used. 


\section{RESULTS}

Table 1: Table showing Mean, SD scores for Adolescents in Joint and Nuclear Families on the Powerful Other, Chance and Individual Control Factor of Locus of Control and Loneliness

\begin{tabular}{|l|l|l|l|l|l|l|l|l|l|}
\hline \multirow{2}{*}{ Family Type } & \multirow{9}{*}{$\mathrm{N}$} & \multicolumn{3}{|l|}{ Variables } \\
\cline { 3 - 10 } & & $\begin{array}{l}\text { Powerful other } \\
\text { locus of control }\end{array}$ & $\begin{array}{l}\text { Chance control } \\
\text { locus of control }\end{array}$ & $\begin{array}{l}\text { Individual control } \\
\text { locus of control }\end{array}$ & \multicolumn{2}{l}{ Loneliness } \\
\cline { 2 - 11 } & & Mean & SD & Mean & SD & Mean & SD & Mean & SD \\
\hline $\begin{array}{l}\text { Nuclear } \\
\text { families }\end{array}$ & 60 & 22.60 & 4.88 & 24.13 & 4.89 & 29.63 & 3.40 & 99.06 & 12.04 \\
\hline Joint families & 60 & 22.26 & 5.83 & 23.71 & 5.55 & 30.90 & 4.15 & 95.60 & 13.98 \\
\hline
\end{tabular}

The tabular presentation of data shows the Mean and the SD scores of adolescents in nuclear and joint families on powerful others(22.60, 22.26), chance control $(24.13,23.71)$ and individual control $(29.63,30.90)$ factor of locus of control and also of loneliness $(99.06,95.60)$ respectively. It means that adolescents from joint and nuclear families have similar effect of powerful others on their outcomes in life. It also indicate that adolescents in nuclear families have more influence of chance or fate on their outcomes in life than joint families adolescent. It also revealed that adolescents in joint families have higher internal locus of control than adolescents in nuclear families. It also shows that nuclear family adolescents have more loneliness than joint family adolescents.

Table 2: Table showing the Anova Scores of Adolescents Belonging to Joint and Nuclear on Powerful Factor of Locus of Control

\begin{tabular}{|l|l|l|l|l|l|}
\hline \multicolumn{2}{|l|}{ Source } & $\begin{array}{l}\text { Sum of } \\
\text { Squares }\end{array}$ & df & $\begin{array}{l}\text { Mean } \\
\text { Square }\end{array}$ & F \\
\hline \multirow{3}{*}{ LOCP } & $\begin{array}{l}\text { Between } \\
\text { Groups }\end{array}$ & 23.117 & 2 & 11.558 & \multirow{2}{*}{.398} \\
\cline { 2 - 5 } & Within Groups & 3396.350 & 117 & 29.029 & \\
\cline { 2 - 5 } & Total & 3419.467 & 119 & & \\
\hline
\end{tabular}

The table shows the results of one-way analysis of variance (ANOVA) which was calculated on powerful others factors of locus of control adolescents belonging to joint and nuclear families. The analysis between the two variables was not found to be significant, $(F(2,117)=.398, \mathrm{p}=$ $.672)$ 
Loneliness and Locus of Control among Adolescents Belonging To Nuclear and Joint Families

Table 3: Table showing the Anova Scores of Adolescents Belonging to Joint and Nuclear on the Chance Control Factor of Locus of Control

\begin{tabular}{|l|l|l|l|l|l|}
\hline \multicolumn{2}{|l|}{ Source } & $\begin{array}{l}\text { Sum of } \\
\text { Squares }\end{array}$ & df & $\begin{array}{l}\text { Mean } \\
\text { Square }\end{array}$ & F \\
\hline \multirow{3}{*}{ LOCC } & Between Groups & .200 & 2 & .100 & \\
\cline { 2 - 5 } & Within Groups & 3238.125 & 117 & 27.676 & \multirow{2}{*}{.004} \\
\cline { 2 - 5 } & Total & 3238.325 & 119 & & \\
\hline
\end{tabular}

The results of the above table show one-way analysis of variance (ANOVA), which was calculated on chance control factors of locus of control adolescents belonging to joint and nuclear families. The analysis between the two variables was not found to be significant, ( $F$ $(2,117)=.004, \mathrm{p}=.996)$

Table 4: Table showing the Anova Scores of Adolescents Belonging to Joint and Nuclear on Individual Control Factor of Locus of Control

\begin{tabular}{|l|l|l|l|l|l|}
\hline \multicolumn{2}{|l|}{ Source } & $\begin{array}{l}\text { Sum of } \\
\text { Squares }\end{array}$ & df & $\begin{array}{l}\text { Mean } \\
\text { Square }\end{array}$ & F \\
\hline \multirow{3}{*}{ LOCI } & $\begin{array}{l}\text { Between } \\
\text { Groups }\end{array}$ & 2.817 & 2 & 1.408 & \\
\cline { 2 - 5 } & Within Groups & 1748.650 & 117 & 14.946 & .094 \\
\cline { 2 - 5 } & Total & 1751.467 & 119 & & \\
\hline
\end{tabular}

The table shows the results of one-way analysis of variance (ANOVA) which was calculated on individual control factors of locus of control adolescents belonging to joint and nuclear families. The analysis between the two variables was not found to be significant, $(F(2,117)=.094, \mathrm{p}=$ .910)

Table 5: Table showing the Anova Scores of Adolescents Belonging to Joint and Nuclear Families on Loneliness Factor

\begin{tabular}{|l|l|l|l|l|l|}
\hline \multicolumn{2}{|l|}{ Source } & $\begin{array}{l}\text { Sum of } \\
\text { Squares }\end{array}$ & df & $\begin{array}{l}\text { Mean } \\
\text { Square }\end{array}$ & F \\
\hline \multirow{3}{*}{ Loneliness } & $\begin{array}{l}\text { Between } \\
\text { Groups }\end{array}$ & 1515.217 & 2 & 757.608 & \\
\cline { 2 - 5 } & $\begin{array}{l}\text { Within } \\
\text { Groups }\end{array}$ & 18941.450 & 117 & 161.893 & \multirow{2}{*}{$4.680 * *$} \\
\cline { 2 - 5 } & Total & 20456.667 & 119 & & \\
\hline
\end{tabular}

A one-way analysis of variance (ANOVA) was calculated on loneliness in adolescents belonging to joint and nuclear families. The analysis between the variables was found to be significant, $(F$ $(2,117)=4.68, \mathrm{p}<0.01)$ 


\section{DISCUSSION}

The title of the present research is "loneliness and locus of control among adolescents belonging to nuclear and joint families”. For this a sample of 120 school going adolescents (60 boys and 60 girls both belonging to nuclear and joint families) were taken. The tool used for the research was Locus of Control Scale Indian Adaptation of Levensons Scale and Perceived Loneliness Scale. For the present research mean, standard deviation and ANOVA was used to do the statistical analysis.

In the present research the findings which came out were that there is no significant difference between powerful others, chance control (external factors) and adolescents in nuclear and joint families and similarly no significant difference between individual control (internal factors) and adolescents belonging to nuclear and joint families. The findings also show that there is a significant difference between adolescent belonging to nuclear and joint families and loneliness. It also showed that adolescents belonging to nuclear families have more external locus of control than adolescents in joint families whereas adolescents belonging to joint families have more internal locus of control. The finding also showed that adolescents in nuclear families were lonelier than adolescents in joint families.

Family structure is conceptualized as the configuration of role, power and status, and relationships. The traditional family is the one living jointly and inclusive of members from different generations. The nuclear type of family is the one, in which the group consists of a male, his wife and their children.

As when adolescents start to move beyond the circle of family to groups and school, they may encounter rejection by peers. When faced with such situation, indeed they are vulnerable to loneliness.

Loneliness is considered to be a universal phenomenon by every individual and has experienced it from time to time. It is the distress that occurs when one's social relationships are perceived as being less satisfying than what is desired (Peplau \& Perlman, 1982)

The analysis showed that there is a significant difference between loneliness and adolescents belonging to joint and nuclear families. It also showed that adolescents belonging to nuclear families are lonelier than adolescents in joint families. Similar study done by Selvaraj and Gnanadevan (2012) also stated that students belonging to nuclear family and joint family differ significantly in their in their level of loneliness and the level of loneliness is high for the students belonging to nuclear family than the students belonging to joint family. Javeed (2014) also found out similar results that Nuclear family children have significantly high loneliness than the Joint family children. 


\section{Loneliness and Locus of Control among Adolescents Belonging To Nuclear and Joint Families}

Locus of control is one psychological construct that/which is useful in accounting for individual differences in the ability to adjust to different situation in life. Locus of Control is a measure of how individuals believe they can control their life, and where that control comes from. It is the perceived source of control over the behaviour.

The study showed that there is no significant difference between adolescents belonging to nuclear and joint families and external locus of control factors (such as powerful others and chance control) and also internal locus of control factors (such as individual control). There are some earlier studies which showed similar findings that family size does not have any significant effect on locus of control of adolescents. It also found out that there was no significant difference between children from nuclear and joint families and locus of control. But some studies suggest that locus of control and family has clear relationship with each other such as study done by Khazer and Almajali (2012). The study done by Lazarus, Amber (2007) suggested that adolescents from families whose parents are more internally driven are better adjusted compared to those who are from families with more external control beliefs.

The analysis of the data also showed that there is no significant difference among adolescents belonging to nuclear and joint families on the powerful others and chance control factor of locus of control. Pattankar (2014) also concluded that there lies no significant difference between joint and nuclear families athletes and powerful factor of locus of control. Similarly he also stated that no significant difference was found between non athletes belonging to nuclear and joint families and chance control factor of locus of control.

Research findings also showed that adolescents in nuclear families have more external locus of control (i.e. powerful others and chance factors) as compared to adolescents in joint families. This means that adolescents think that their outcomes are more controlled by powerful others, chance, fate etc. But it is also seen that adolescents who have internal locus of control mostly are brought up in nuclear family sets. Not many studies have been done in this area. But some other studies such as done by Ghumman, Ghumman and Shoaib (2013) reveal that respondents from nuclear families show higher difference in locus of control then joint families.

Mean values also reveal that adolescents in joint families have more internal locus of control (i.e. individual factors) than adolescents in nuclear families. This indicates that individuals believe that internal factors such as hard work and dedication are reason for their success. Related study done by Rehman and Singh, (2015) and Adeoye (2009) reveals that Joint family adolescents have better adaptation skills and have better emotional adjustment levels than adolescents from nuclear families. This can be because adolescents in joint families are able to socialize more and also have more support due to large family structure. 


\section{CONCLUSION AND RECOMMENDATION}

The research result showed that there was significant difference between adolescents in joint and nuclear families and loneliness. It also showed that there was no significant difference between adolescents in different family type and powerful others, chance control and individual control factor of locus of control. For future the research may be extended to other sections of society. Other attributes can be studied that can influence the locus of control and loneliness. Both the variables can be studied in college students. Other variable like socio economic status, and parental relation can be also be studied. Adolescent of urban and rural areas can also be compared to see the effect of environment and other psychological variables.

\section{REFERENCES}

Adas, A. (1999). Educational psychology. 1st Edition. Amman, Jordan: Alfikr House.

Adeoye, AO. (2009). Impact of home types, religion and gender on adolescent social adjustment among Ogun state secondary schools students in Nigeria. Nigerian Journal of Guidance and Counselling, 14(1):154-155

Arnett, J. J. (2007). Adolescence and emerging adulthood: A cultural approach (3rd Ed.). Upper Saddle River, NJ: Prentice Hall.

Attar-Schwartz, S. (2009). Peer sexual harassment victimization at school: The roles of student characteristics, cultural affiliation, and school factors. American Journal of Orthopsychiatry, 79, 407-420.

Basgall, C. R, \& Snyder, G. (1988). Relationship between Material Church Attendance and Adolescent Mental Health and Social Function. American Psychiatric Association, 50, 799-805

Bender, W. N. (1995). Learning Disabilities: Characteristics, identification, and teaching strategies. (2nd Ed.).Needham Heights, Mass: Allyn \& Bacon.

Brennan, T. (1982). Loneliness at adolescence. In L. A. Peplau \& D. Perlman (Eds.), Loneliness: A sourcebook of current theory, research and therapy (pp. 269-290). New York: John Wiley.

Ditommaso, E., Brannen, C., \& Burgess, M. (2005). The universality of relationship characteristics: A cross-cultural comparison of different types of attachment andloneliness in Canadian and visiting Chinesestudents.Social Behavior and Personality, 33, 57-67.

Ghumman, A., Ghumman, S., \& Shoaib, M. (2013). Role of locus control in marital adjustment amongschool teachers: A study of working women in Gujrat-Pakistan. World applied science journal, 25(4), 694-698.

Gürsoy, F., \& Biçakç1, Y. (2006). Study on the Loneliness Level of Adolescents. Journal of Qafqaz, 18; 140-146.

Jain, M., \& Singh, S. (2015). Locus of control and its relationship with mental health and adjustment among adolescent females. Journal of Mental Health and Human Behaviour; 20:16-21. 


\section{Loneliness and Locus of Control among Adolescents Belonging To Nuclear and Joint Families}

Javeed, Q. (2014) Relative Effect of Nuclear Family and Joint Family upon Emotional Intelligence and Loneliness.Golden research thoughts, volume no 3, issue 9, 1-4.

Jha, P.K. (1997). Manual for Perceived Loneliness Scale (L-Scale). National Psychological Corporation: Agra.

Khazer, H., \& Almajali, S. (2012). The relationship of family upbringing style with locus of control of preparatory school learners in Jordon. European Scientific Journal, Vol 8, No. 13. $126-142$.

Kulaksızoğlu, A. (2001). Psychology of Adolescence. Istanbul: Remzi Bookstore. (117-129).

Lau, S., \& Kong, C. K. (1999). The acceptance of lonely others: Effects of loneliness and gender of the target person and loneliness of the perceiver. Journal of Social Psychology, 139, 229-241.

Lazarus, A, D. (2007). Family locus of control and adolescent resilience and adjustment. (doctoraldissertation). Retrieved from http://search.proquest.com/docview/304747113.

Marsh, H. W. \& Richards, G. E. (1987). The multidimensionality of the Rotter I-E Scale and its higher order structure: An application of confirmatory factor analysis. Multivariate Behavioral Research. 22, 39-69.

Mclean, B. G. (2007). Predicting the Performance of Dental hygienic behaviours. Anexamination of the fishbein and ajzen model and self-efficacy expectations. Journal of Appeared social psychology. 18, $114-128$.

Nelsen, J. \& Lott, L. (2001). Positive for adolescents discipline (Translated by B. Ozturk). Istanbul: White Publishing.

Pattankar, J, S. (2014). Sports psychology, Solapur, Maharashtra, India: Laxmi Book Publication. Ponzetti, J. J. (1990). Loneliness among college students. Family Relations, 39, 336-340

Perlman, D., \& Peplau, L.A. (1981). Toward a social psychology of loneliness. In S. W. Duck B R. Gilmour (Eds.), Personal relationships: Vol. 3. Personal relationships in disorder (pp. 3 1-56). London: Academic Press.

Peplau, L. A., \& Perlman, D. (1982). Perspectives on loneliness. In L. A. Peplau \& D. Perlman (Eds.), Loneliness: A Sourcebook of Current Theory, Research and Therapy (pp. 1-20). New York: John Wiley \& Sons.

Rehman, R., \& Singh, H. (2015). Family Type and Adjustment Level of Adolescents: A Study. Journal of International Dental and Medical Research; 1(6):22-25.

Rotter, Julian B. (1954). Social learning and clinical psychology. New York: Prentice - Hall, 1954.

Rutter, M., \& Smith, D. (1995). Psychosocial Disorders in Young People. Chichester: Wiley.

Sardogan E. M., Kaygusuz, C., \&Karahan, T. F. (2006). A Human Relations Skills Training Program, University Students' Locus of Control Levels, Mersin University Journal of the Faculty of Education, 2 (2), 184-194.

Selvaraj, A., \& Gnanadevan, R. (2012). A Study on Loneliness of Normal School Students Studying Higher Secondary. Golden Research Thoughts, Volume 2, Issue. 3, 1-4.

Shinde, G., \& Bhoi, R, M. (2014). Comparative Study of Social Adjustment Based on Family Type. Scholarly Research journal for interdisciplinary studies, vol II/XY, 2561-2580. 


\section{Loneliness and Locus of Control among Adolescents Belonging To Nuclear and Joint Families}

Shukla, \&Mamatha, (1991). Development of Cognitive Style and Locus of Control as a Function of Child - Rearing Practices. J.P. Sharma, (Ed.) Fifth Survey of Research in Education (1988 - 92), Vol. II, pp. 1001.

Spielberger, C.D., \& Jolley, M. (1973). The effects of locus of control and anxiety on verbal conditioning. Journal of Personality, 41, 443-456.

Usoroh. Comfort I., Akpan., David, I., Amadi, N, B., Ezenwa., \& Happiness C. (2014). Comparative Study of the Effect of Family Types on Social Adjustment of Adolescent in Aba, Abia State. Civil and Environment Research,

Vol.6, No.8, 147-151.

Vernberg, E., Ewell, K., Beery, S., \& Abwender, D. (1994). Sophistication of adolescents' interpersonal negotiation strategies and friendship formation after relocation: A naturally occurring experiment. Journal of Research on Adolescence, 4, 5-19.

Vohra, S. (1992). Manual for the Levensons Locus of Control Scale. Psy-com Services, New Delhi.

Zubrick, S.R., Silburn, P.B., Burton, P., \& Blair, E. (2000). Mental health disorders in children and young people: Scope, cause and prevention. Australian and New Zealand Journal of Psychiatry, 34, 570-578. 